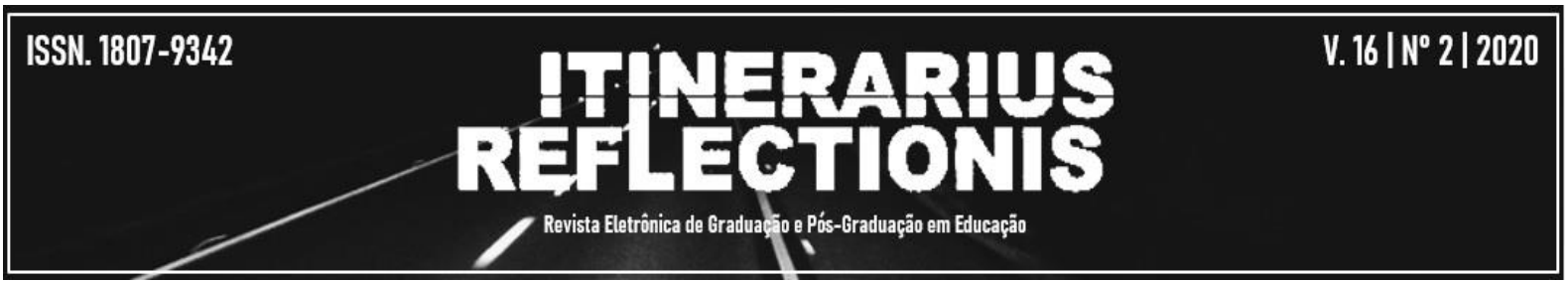

\title{
Contribuições da Neuropsicopedagogia no processo de envelhecimento: prevenção do declínio cognitivo e melhoria de qualidade de vida
}

\author{
Simone de Oliveira ${ }^{1}$ \\ Anderson Alves Santos ${ }^{2}$
}

Resumo A sociedade contemporânea trouxe mudanças importantes na forma de pensar, relacionar-se no mundo e principalmente na busca incessante por melhoria na qualidade de vida. O processo de envelhecimento é discutido com afinco e muitos estudiosos se debruçam para que as pessoas cheguem numa idade mais avançada em melhores condições, tanto física quanto mentalmente. Neste contexto, este projeto pretende realizar um estudo de revisão bibliográfica sobre a prevenção do declínio cognitivo e a importância da Neuropsicopedagogia que, com ferramentas específicas, pode auxiliar o processo de envelhecimento saudável, minimizando os impactos inerentes a chegada da idade. A metodologia envolveu pesquisa bibliográfica, descritiva e documental, baseando-se em Gil, Godoy, Prodanov e Freitas. Os resultados demonstram que ocorreram poucas publicações em 2018/2019, em revistas de Psicologia, a respeito de ações que busquem a melhor qualidade de vida e que atuem na prevenção do declínio cognitivo do processo de envelhecimento.

Palavras-chave: Estimulação cognitiva. Envelhecimento saudável. Declínio cognitivo.

\section{Contributions of Neuropsycopedagogy in the aging process: Prevention of cognitive decline and improvement of quality of life}

\begin{abstract}
Contemporary society has brought important changes to people in the way they think, relate in the world and especially in the incessant search for improvement in quality of life. The aging process is hard discussed and many scholars look to people to reach an older age in better conditions, both physically and mentally. In this context, this project intends to carry out a literature review study on the prevention of cognitive decline and the importance of Neuropsychopedagogy that, with specific tools, can help the healthy aging process, minimizing the impacts inherent to the arrival of age. The methodology involved bibliographical, descriptive and documentary research, based on Gil, Godoy, Prodanov and Freitas. The results show that there have been few studies published in 2018/2019, in Psychology journals, regarding actions that seek the best quality of life and that act to prevent cognitive decline in the aging process.
\end{abstract}

Keywords: Cognitive Stimulation. Healthy aging. Cognitive decline.

\section{INTRODUÇÃO}

Tomando por base que em 2012 a população brasileira com 60 anos ou mais era de 25,4 milhões, e que nos últimos cinco anos esse quantitativo aumentou em 4,8 milhões de novos idosos, percebe-se um crescimento de $18 \%$ em 05 anos e chegando à casa dos 30,2

\footnotetext{
${ }^{1}$ Secretaria Municipal de Educação de Betim - MG Psicopedagoga - Clínica Institucional - MG. solbhmg@yahoo.com.br

${ }^{2}$ Instituto Federal de Educação, Ciência e Tecnologia de Minas Gerais - IFMG. alvessanto@gmail.com
} 


\section{ReFLETHONS}

milhões (BRASIL, 2017). Ainda de acordo com o Brasil (2017), na década de 2060, mais de $25 \%$ da população deverá ter mais de 65 anos.

De acordo com informação da Agência FAPESP (2019), o Brasil, apesar de possuir 14\% da população com mais de 60 anos, ainda continua sendo um país de jovens; entretanto, "a tendência é que siga envelhecendo cada vez mais rápido.” E continua: "[...] o país não se preparou para o aumento na proporção de idosos, que era de 10,8\% em 2010 e de apenas 4,1\% em 1940." No entendimento de Alexandre Kalache, médico epidemiologista e presidente do Centro Internacional de Longevidade - Seção Brasil, “enquanto os países desenvolvidos enriqueceram primeiro, para depois envelhecer, nós estamos envelhecendo com pobreza. E não só com pobreza, mas com muita desigualdade" (AGÊNCIA FAPESP, 2019).

A partir destas informações, percebe-se que os atuais sistemas de investimento em saúde, de modo geral, não estão preparados para tal realidade, tornando-se importante a promoção de ações que proporcionem um envelhecimento saudável, mesmo sendo um desafio para todas as esferas envolvidas neste contexto. Se envelhecer, é um processo natural e inerente ao ser humano, torna-se necessário preparar-se para enfrentar as mudanças físicas e psíquicas que possam comprometer a longevidade.

Dessa forma, o objetivo desta pesquisa foi elencar evidências do que já foi discutido em artigos publicados em revistas brasileiras da área de Psicologia nos anos de 2018-2019, a respeito da Neuropsicopedagogia voltada ao processo de envelhecimento, realizando-se um levantamento bibliográfico sobre o mote da presente pesquisa. Esse período de tempo foi definido por se tratar do último período de avaliação das Revistas, pelo Sistema Qualis. Foram encontrados 413 registros, sendo 69 dedicadas ao tema Psicologia - em áreas distintas. Destas 69, apenas 04 revistas possuem artigos referentes ao assunto.

\section{MATERIAIS E MÉTODOS}

Foram encontrados 413 registros, sendo 69 dedicadas ao tema Psicologia - em áreas distintas. Destas 69, apenas 04 revistas possuem artigos referentes ao assunto. A presente pesquisa se baseou em pesquisa exploratória que, de acordo com o entendimento de Prodanov e Freitas (2013, p. 51-52), é quando ela se encontra na fase inicial, tendo 


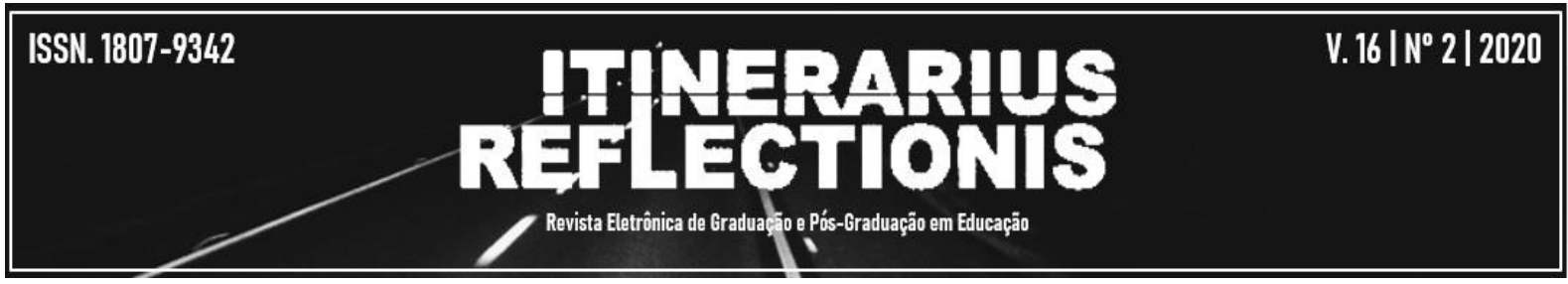

As pesquisas exploratórias, no entender de Gil (2008, p.27) “são desenvolvidas com o objetivo de proporcionar visão geral, de tipo aproximativo, acerca de determinado fato". A abordagem foi qualitativa, pois oferece três diferentes possibilidades para a realização de uma pesquisa: a pesquisa documental, o estudo de caso e a etnografia. No caso da presente pesquisa, o procedimento adotado para a coleta de dados foram a pesquisa bibliográfica e a documental. Para Bailey (1982), em várias situações de investigação, a pesquisa documental se mostra pertinente e vantajosa.

Para Godoy (1995, p. 21), os documentos são uma fonte não-reativa, as informações que eles contêm permanecem as mesmas, mesmo após longo tempo. Eles são considerados como uma "fonte natural de informações à medida que, por terem origem num determinado contexto histórico, econômico e social, retratam e fornecem dados sobre esse mesmo contexto. Não há, portanto, o perigo de alteração no comportamento dos sujeitos sob investigação."

A coleta de dados se deu pela análise de artigos publicados em revistas brasileiras de Psicologia, publicadas em 2018-2019, classificadas como Qualis A2 na Plataforma Sucupira. A classificação dos periódicos se deu baseando-se no quadriênio 2013-2016.

\section{FUNDAMENTAÇÃO TEÓRICA}

Levando-se em consideração que o envelhecimento é um processo intrínseco e extrínseco, no qual há uma progressiva deterioração da função fisiológica, resultando numa perda de viabilidade e aumento da vulnerabilidade, é necessário atentar para possíveis atuações que retardem ou minorem os problemas relativos a esse fato.

Para Simões (2006), o envelhecimento tem como origem um período anterior ao da própria existência; ou seja: começa-se a envelhecer assim que se nasce. Ainda para este mesmo autor, o envelhecer pode ser vivenciado de várias maneiras, tomando como ponto de referência o gênero, classe social, local onde se vive e mesmo o nível educacional possui.

A Organização Mundial da Saúde (OMS) define idoso, nos países desenvolvidos, como o indivíduo que 65 anos ou mais; e aquele com 60 anos ou mais, nos países subdesenvolvidos. A pessoa idosa na maioria das vezes é assim definida, independente de se levar em conta seu estado físico ou psicológico. 


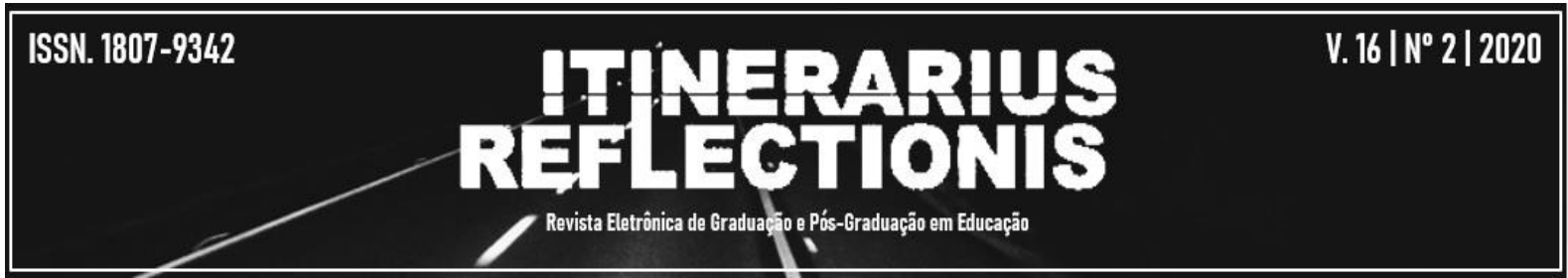

No entender de Araújo e Carvalho (2005, apud OLIVEIRA et al., 2014, p.52), até o século XIV a velhice era percebida como um ato de mendicância, visto que o idoso tinha como maior característica a condição de não poder manter-se financeiramente. Por isso, o 'velho' passava a imagem de não produtividade - era visto mais como um peso, um fardo sendo, dessa forma, "denominado velho aquele que não era inserido na sociedade, embora se usasse o termo velhote para caracterizar o velho que tivesse sua imagem associada a um bom cidadão".

Muito mais que mudanças físicas, o envelhecer traz consigo diversas alterações, principalmente psicológicas, tais como: dificuldade para entender e enfrentar de novos afazeres, desmotivação, depressão em diferentes graus, diminuição da autoestima e outras (LIMA; DELGADO, 2010).

Deve-se entender que no "ato" de envelhecer, as mudanças psicológicas e sociais, são amplas e podem ser percebidas em diferentes idades físicas e, ou cerebrais, ocorrendo com maior ou menor grau de acordo com a genética de cada pessoa e, claro, com o modo de vida que ela possui (ZIMERMAN, 2000). Conforme o entendimento de Jacob (2007, p. 3), no decorrer do processo de envelhecimento,

[...] as capacidades de adaptação do ser humano vão diminuindo, tornando-o cada vez mais sensível ao meio ambiente que, consoante às restrições implícitas ao funcionamento do idoso, pode ser um elemento facilitador ou um obstáculo para a sua vida.

As transformações pelas quais passa a sociedade moderna são percebidas quando comparadas e, ou analisadas em relação à forma como os indivíduos organizam suas vidas: elas dedicam parte do seu tempo à vida profissional, deixando para trás o seu tempo de lazer muito bem discutido por Domenico De Masi, em 'O ócio criativo' - e, dessa forma, não exercitando as funções cerebrais como um todo. Esse "descuido" ocasiona, muitas vezes, um envelhecer problemático, pois deixa de estimular as funções cognitivas e, ocasionalmente, torna a velhice ou o envelhecer bem mais complicado do que se tivesse trabalhado preventivamente tais funções ao longo do tempo.

A Neurociência vem colaborando, na última década, com novas descobertas sobre o funcionamento do cérebro humano; e como um trabalho de estimulação cognitiva pode contribuir efetivamente para melhorar o desempenho nas funções executivas superiores (atenção, memória, raciocínio, concentração e percepção); auxiliando no processo de aprendizagem do indivíduo, bem como melhorar a qualidade de vida e bem-estar dos idosos. 


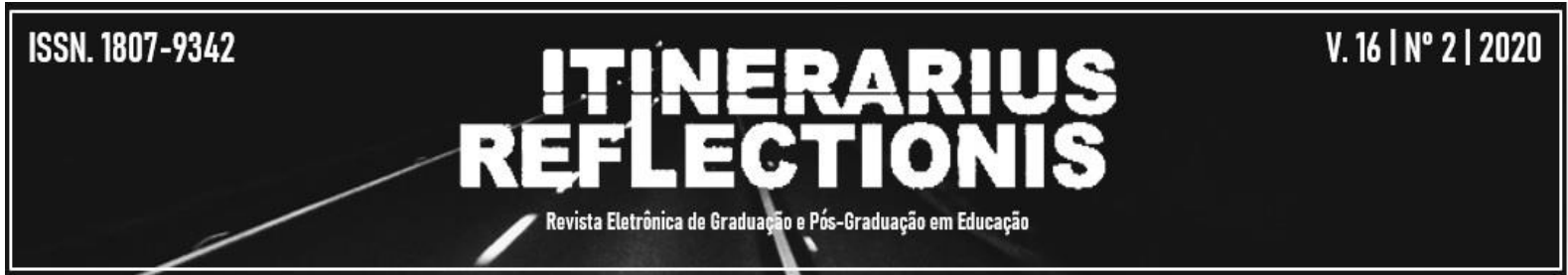

As tarefas realizadas diariamente também pressupõem a atividade cerebral (PIRES e FERREIRA, 2018, p. 153). Os primeiros autores citam que, de acordo com Squire e Kandel (2003, apud RUSSO, 2015, p.49) as funções cognitivas estão distribuídas:

No córtex cerebral, que é dividido em quatro regiões: lobo frontal, que está envolvido com o planejamento e com o movimento voluntário; o lobo parietal, com as sensações da superfície corporal e percepção espacial; o lobo occipital, com a visão; e o lobo temporal, com a audição, a percepção visual e a memória. Os processos mentais constituem os fundamentos da percepção, da atenção, da motivação, da ação, do planejamento e do pensamento, além da própria aprendizagem e memória.

Na compreensão de Torres e Desfilis (1997, apud RUSSO, 2015, p.49), percepção, atenção e memória são entendidas "como processos mediante os quais o sujeito é capaz de codificar, armazenar e recuperar a informação." Lima e Murai (2005) ressaltam que é muito frequente a ideia de velhice estar associada à doença e à incapacidade (LIMA \& MURAI, 2005, apud OLIVEIRA et al., 2014, p. 66), dando a entender que

[...] as questões sociais relevantes para os estudos sobre o envelhecer humano, são deixadas de lado, abrindo espaço para que além do desgaste físico, outras situações como o sentimento de exclusão, inutilidade, sejam vistos de forma natural. Esse estado de pouca importância do idoso significa a perda de sua dignidade, um não reconhecimento de seus direitos à igualdade, seja na saúde, moradia e outras condições necessárias para uma sobrevida dentro dos parâmetros de cidadania.

Assim, é muito importante a função e ação do Neuropsicopedagogo junto às variadas intervenções realizadas no intuito de promover a melhoria na qualidade de vida, fundamentado na busca constante do melhor horizonte de vivência da pessoa idosa, para que ela possa alcançar suas perspectivas de "final de vida", de seus relacionamentos, de seus lazeres e ocupações. Ressalta-se que essa aprendizagem mencionada acima é a aprendizagem de novas atividades e atitudes que resultarão na melhoria da qualidade de vida do idoso.

Por qualidade de vida, a presente pesquisa se baseará na definição dada pela Organização Mundial da Saúde (2008, p. 1585): “a percepção do indivíduo de sua posição na vida, no contexto de sua cultura e dos sistemas de valores da sociedade em que vive e em relação aos seus objetivos, expectativas, padrões e preocupações." Salienta-se que esta conceituação é bem generalista, possivelmente influenciada por questões de saúde física, estado psicológico, tipo e qualidade de independência e relações sociais que o indivíduo idoso possua. 


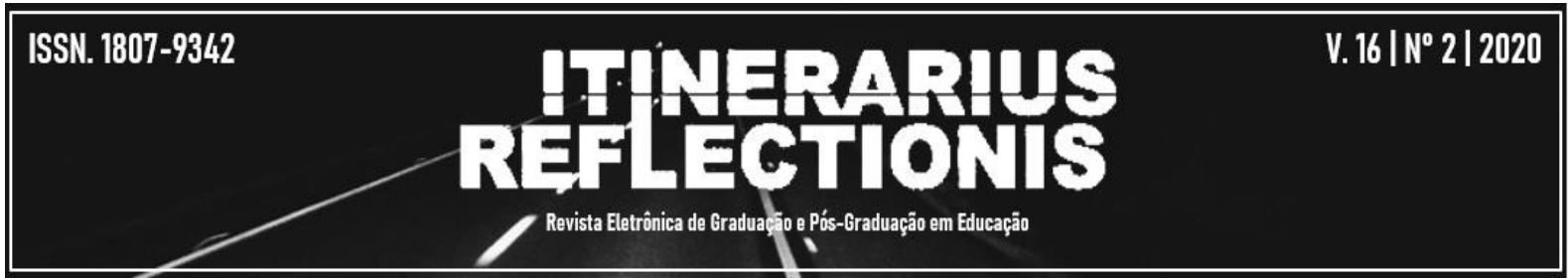

Guedes (2009) salienta que 'qualidade de vida na velhice' já era usada na gerontologia, na década de 1980, e cita o entendimento de Lawton (1983) a esse respeito, em que "qualidade de vida na velhice é definida como a avaliação multidimensional vinculada a critérios socionormativos e intrapessoais, a respeito das relações atuais, passadas e prospectivas entre o indivíduo maduro ou idoso e o seu ambiente." Nota-se mais objetividade nessa definição do que aquela dada pela OMS.

Independente da compreensão entendida nas conceituações acima é importante analisar as dimensões vividas pelo idoso, referentes ao ambiente físico, à competência comportamental, à qualidade de vida percebida e ao bem-estar subjetivo, dentro da visão da Neuropsicopedagogia. Essas dimensões, na concepção de Neri (2005, apud GUEDES, 2009), podem ser descritas da seguinte forma:

- Ambiente físico: abrange aspectos externos ao sujeito, referindo-se ao contexto físico, ecológico e ao construído pelo homem, influenciando suas competências comportamentais, emocionais e cognitivas.

- Competência comportamental: refere-se à avaliação do comportamento do sujeito quanto à saúde, funcionalidade física, cognição, interação social e uso do tempo.

- Qualidade de vida percebida: relaciona-se à própria vida; ou seja, pela influência agregada dos valores e expectativas tanto pessoais quanto sociais do próprio sujeito.

- Bem-estar subjetivo: diz respeito à avaliação pessoal a respeito das dimensões acima, buscando entender o quão importante é a satisfação com a própria vida e com a satisfação geral sobre determinados aspectos da vida, principalmente em fatores relacionados aos indicadores cognitivo e emocional.

Daí a importância, mais uma vez, do estudo de como a Neuropsicopedagogia atua para entender e proporcionar uma melhoria na qualidade de vida durante a velhice. Diante do exposto, cabem algumas indagações: Considerando o envelhecimento das pessoas, muitas vezes sem o devido apoio psicológico para entenderem e, ou aceitarem esse processo, não seria interessante que elas tivessem a possibilidade de se "apoiarem" em intervenções que possam ajudar neurologicamente o cérebro? Existem intervenções que promovam estimulações cognitivas em idosos e em pessoas adultas, que buscam se prevenir para um envelhecimento mais saudável? E acreditando que elas existam, qual a função da neuropsicopedagogia, nesse tipo de intervenção? Que outras possibilidades são possíveis de 


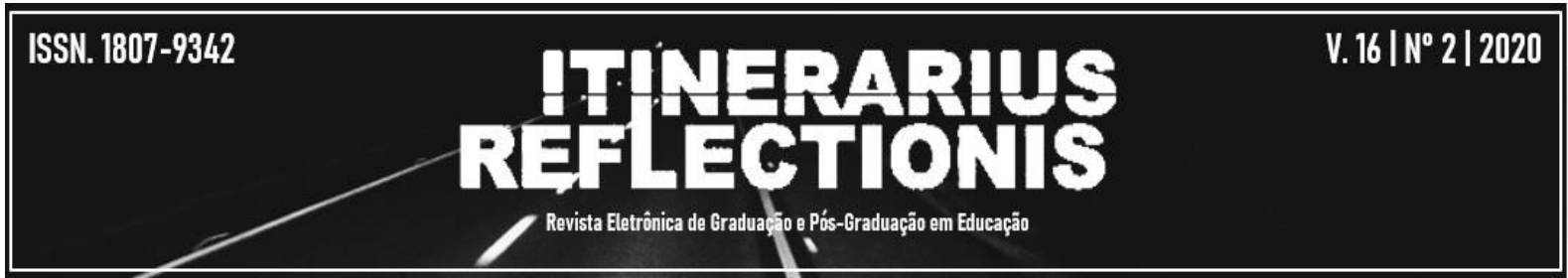

se trabalhar, visando à melhoria da qualidade de vida e, consequentemente, a saúde física e mental dos idosos?

\section{RESULTADOS E DISCUSSÕES}

Na Revista 'Avaliação Psicológica' (2018) foi encontrado apenas um artigo ("Fatores associados à sintomatologia depressiva em idosos") que trata dos fatores associados à sintomatologia depressiva em idosos, o que pode resultar na pior qualidade de vida dos mesmos. Na pesquisa deste trabalho foram investigados 112 idosos, com idade média de 67 anos, e que eram atendidos nos serviços de atenção básica de saúde. Os resultados apontaram a presença de sintomas depressivos em 35,7\% (40) dos participantes. Um dado curioso foi que as mulheres apresentaram mais sintomas e maior comprometimento da capacidade funcional. Possivelmente alguns dos fatores estavam relacionados ao fato que elas moravam sozinhas e que a maior dependência funcional e déficits cognitivos estavam associados à presença de sintomas depressivos. Deve-se ressaltar que, se houver o conhecimento da presença de fatores associados aos sintomas depressivos em idosos, pode-se tentar a promoção de ações que objetivem a qualidade de vida nesta população.

Vislumbrou-se que na "Revista Ciência \& Saúde Coletiva" 03 artigos que abordavam a temática sobre envelhecimento e comprometimento cognitivo. $\mathrm{O}$ primeiro artigo, de 2018, (“Qualidade de vida e níveis de atividade física de moradores de residências terapêuticas do sul do Brasil") analisa prioritariamente a qualidade de vida relacionada à atividade física em portadores de transtornos mentais que eram moradores em residências terapêuticas. Os resultados deste trabalho ressaltam que os pesquisados não exercem atividades físicas rotineiras, devido à falta de incentivo e oportunidades em tais residências.

O segundo trabalho (publicado em 2019), intitulado "Influencia de las actividades en la calidad de vida de los ancianos: revisión sistemática", buscou identificar quais atividades ou intervenções proporcionavam mudanças na qualidade de vida de idosos. Para isso os autores estudaram 27 artigos publicados entre 2010 e 2015, em que compararam a qualidade de vida de idosos antes e depois da realização de alguma intervenção física, educacional ou ambas. No terceiro artigo, "O imperativo de cuidar da pessoa idosa dependente", a autora apresenta uma visão de como se dá o envelhecimento no Brasil e mostra informações que fornecem suporte para a necessidade de criação de instrumentos para trabalhar com o aumento expressivo da população idosa, principalmente dos que perdem sua autonomia física, cognitiva, mental/emocional e social. 


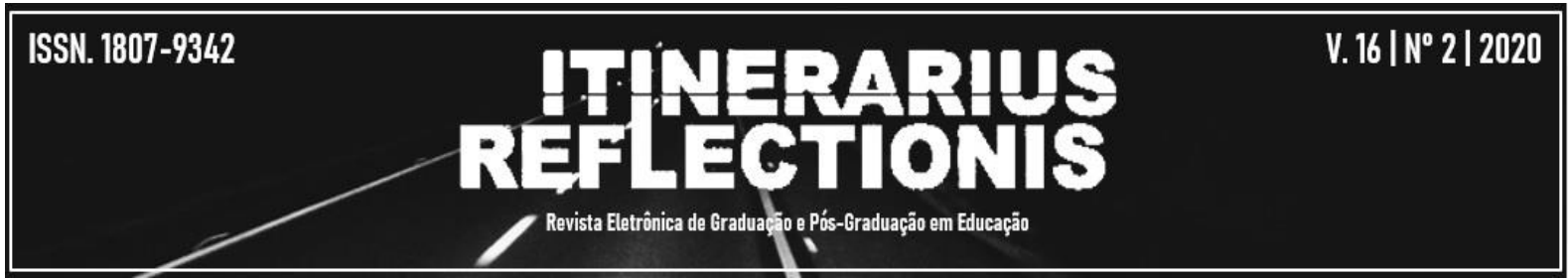

$\mathrm{O}$ artigo publicado no 'Brazilian Journal of Medical and Biological Research' (em 2019, intitulado "A newly designed intensive caregiver education program reduces cognitive impairment, anxiety, and depression in patients with acute ischemic stroke") focava na avaliação do efeito de um programa intensivo de educação para cuidadores, no intuito de que eles atuem para diminuição do comprometimento cognitivo, da ansiedade e da depressão em pacientes que tiveram AVC isquêmico agudo. Ou seja, o objetivo era avaliar o programa em si e não a situação e, ou as metodologias existentes e colocadas em prática para melhoria da qualidade de vida e prevenção do declínio cognitivo dos pacientes.

A revista "Psicologia: Teoria e Prática" publicou, em 2019, o artigo "Efeito da terapia cognitivo-comportamental um ano após tratamento para adultos e idosos com transtorno depressivo maior", o qual tratou da necessidade de se explicitar mais sobre a manutenção dos resultados pós-tratamentos da terapia cognitivo-comportamental para o transtorno depressivo maior; e para isso os autores analisaram se o tratamento psicoterápico era efetivo num período de 06 a 12 meses após a intervenção.

Percebeu-se que, embora todos os trabalhos acima sejam de suma importância para a questão de melhoria de vida em idosos, muito pouco foi abordado em relação às contribuições específicas da Neuropsicopedagogia no processo de envelhecimento. Diante disso, torna-se de fundamental importância buscar estudos empíricos que sinalizem para ações de estimulação cognitiva e contribuições significativas, bem como o resultado de tais intervenções em idosos pesquisados.

\section{CONCLUSÕES}

Foram encontrados apenas seis artigos publicados, referentes à temática desta pesquisa: melhoria da qualidade de vida no envelhecimento. Das quatro revistas que publicaram artigos pertinentes, nenhuma é específica da Neuropsicopedagogia; todas são da área da saúde coletiva ou específicas (pesquisas médicas e psicológicas): 'Revista 'Avaliação Psicológica', 'Revista Ciência \& Saúde Coletiva', 'Brazilian Journal of Medical and Biological Research' e 'Revista Psicologia: Teoria e Prática'. Muito pouco foi abordado em relação às contribuições específicas da Neuropsicopedagogia no processo de envelhecimento.

Conclui-se que a elevada prevalência de suspeita de déficit cognitivo, depressão e de demência revelada no presente estudo deve remeter para a reflexão sobre a adequação dos 


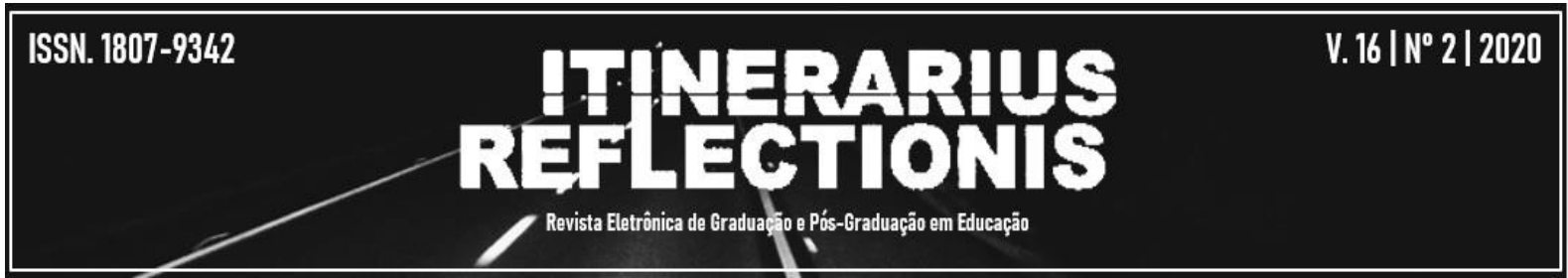

cuidados prestados e sobre a ausência/escassez de pesquisas e, ou programas de estimulação cognitiva nas estruturas residenciais para idosos.

Nesse sentido, é importante implementar avaliação cognitiva regular e instituir programas de intervenção que promovam a conservação e melhoria do funcionamento cognitivo em pessoas idosas institucionalizadas ou não. Ações que possam ajudar pacientes e familiares a conviver e superar as limitações impostas pelos déficits cognitivos, bem como suas consequências físicas, emocionais e sociais.

\section{REFERÊNCIAS}

AGÊNCIA FAPESP. Qualidade de vida é o maior desafio da longevidade. Disponível em: <http://agencia.fapesp.br/qualidade-de-vida-e-o-maior-desafio-da-longevidade/30207/>. Acesso em: 09 abr. 2019.

\section{BAILEY, K. D. Methods of social research. 2. ed. New York: Free Press, 1982.}

BRASIL. Instituto Brasileiro de Geografia e Estatística. Número de idosos cresce $18 \%$ em 5 anos e ultrapassa 30 milhões em 2017. Disponível em: <https://agenciadenoticias.ibge.gov. br/agencia-noticias/2012-agencia-de-noticias/noticias/20980-numero-de-idosos-cresce-18-em5-anos-e-ultrapassa-30-milhoes-em-2017> Acesso em 06 abr. 2019.

Projeção da População 2018: número de habitantes do país deve parar de crescer em 2047. Disponível em: < https://agenciadenoticias.ibge.gov.br/agencia-sala-de-imprensa/ 2013-agencia-de-noticias/releases/21837-projecao-da-populacao-2018-numero-de-habitantesdo-pais-deve-parar-de-crescer-em-2047> Acesso em: 06 abr. 2019.

FONTES, M. A. F; FISCHER, C. P. Neuropsicologia e as Funções Cognitivas. São Paulo/SP. 2016. In: PIRES, H. S. R; FERREIRA, B. I. A. S. Neurociências e Compreensão Leitora: Emoção, Atenção, Memória e Funções Executivas. Rev. FSA, Teresina, v.15, n.4, art. 8, p.151-168, jul./ago. 2018. Disponível em: <http://www4.fsanet.com.br/revista/index.php/ fsa/article/view/1586/491491586>. Acesso em: 06 maio. 2019.

GIL, A. C. Métodos e técnicas de pesquisa social. 6. ed. - São Paulo : Atlas, 2008.

GODOY,A. S. Introdução à pesquisa qualitativa e suas possibilidades. RAE - Revista de Administração de Empresas, São Paulo, v. 35, n. 2, p. 57-63, 1995. Disponível em: <http://www.spell.org.br/documentos/ver/12736/pesquisa-qualitativa--tipos-fundamentais>. Acesso em: 02 abr. 2019.

GÓMEZ-MORALES, Abigail et al. Influencia de las actividades en la calidad de vida de los ancianos: revisión sistemática. Disponível em: <http://www.scielo.br/scielo.php?script =sci_arttext\&pid=S1413-81232019000100189\&lng=en\&nrm=iso\&tlng=es $>$. Acesso em: 18 maio. 2019.

GUEDES, D. V. Qualidade de vida de idosos com declínio cognitivo. Dissertação (Mestrado em Psicologia) - Universidade Federal de Juiz de Fora, Juiz de Fora, 2009. Disponível em: <http://www.ufjf.br/ppgpsicologia/files/2010/01/Danielle-ViveirosGuedes.pdf >. Acesso em: 03 maio 2019. 


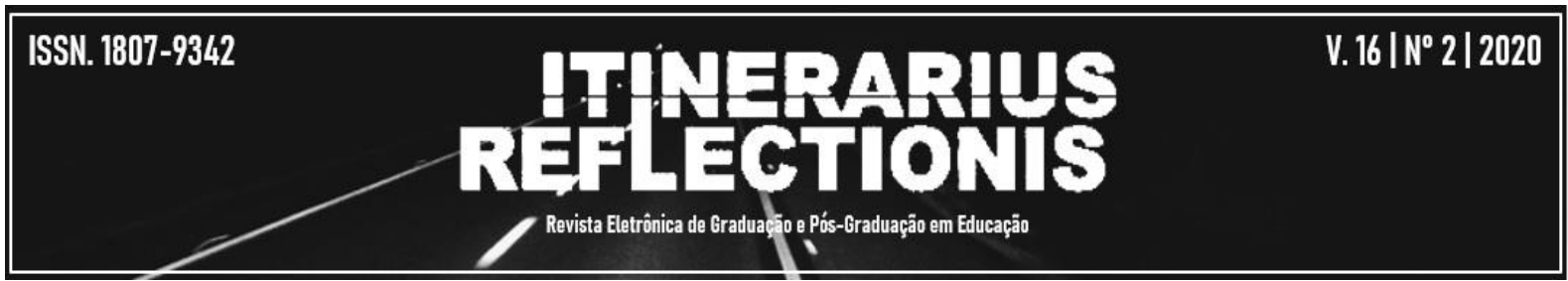

JACOB, L. Animação de idosos. Actividades. Porto: AMBAR. 2007.

KLEIN, Simone K. et al. Qualidade de vida e níveis de atividade física de moradores de residências terapêuticas do sul do Brasil. Disponível em: <http://www.scielo.br/scielo .php?script=sci arttext\&pid= S1413-81232018000501521\&lng=en\&nrm=iso\&tlng=pt $>$. Acesso em: 24 maio. 2019.

LAMPERT, Claudia D. T.; FERREIRA, Vinicius R. T. Fatores associados à sintomatologia depressiva em idosos. Disponível em: <http://pepsic.bvsalud.org/scielo.php?script=sci arttext \&pid=S1677-04712018000200007\&lng=en\&nrm=iso\&tlng=pt >. Acesso em: 29 maio. 2019.

LAWTON, M. P., \& BRODY, E. M. (1969). Assessment of older people: self-maintaining and instrumental activities of daily living. Gerontologist, 9, 179-186. In: GUEDES, D. V. Qualidade de vida de idosos com declínio cognitivo. Dissertação (Mestrado em Psicologia) - Universidade Federal de Juiz de Fora, Juiz de Fora, 2009. Disponível em:

$<$ http://www.ufjf.br/ ppgpsicologia/files/2010/01/Danielle-Viveiros-Guedes.pdf $>$. Acesso em: 03 maio 2019.

LIMA, A. P.; DELGADO, E. I. A Melhor Idade no Brasil: Aspectos Biopsicossociais Decorrentes do Processo de Envelhecimento. Revista de Educação Física. Ji-Paraná, v.1, n.2, pp.76-91, set./out. 2010. Disponível em: <http://www.periodicos.ulbra.br/index.php/ actabrasileira/article/view/3063>. Acesso em: 29 abr. 2019 .

MINAYO, Maria C. de S. O imperativo de cuidar da pessoa idosa dependente. Disponível em: <http://www.scielo.br/scielo.php?script=sci_arttext\&pid=S1413-81232019000100247\&

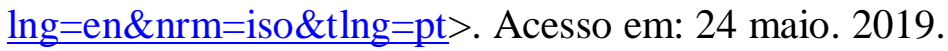

OLIVEIRA, N. S. et al. Percepção dos Idosos sobre o Processo de Envelhecimento. ID on line REVISTA DE PSICOLOGIA. Disponível em: 〈http://idonline.emnuvens.com.br/id〉 . Acesso em: 09 abr. 2019.

ORGANIZAÇÃO MUNDIAL DA SAÚDE. The World Health Organization Quality of Life Assessment (WHOQOL). Development and general psychometric properties. Social Science Medicine, 46. p.1569-1585. Disponível em: <https://www.sciencedirect.com/ science/article/abs/pii/S0277953698000094?via\%3Dihub> Acesso em: 03 jun. 2019.

PIRES, H. S. R; FERREIRA, B. I. A. S. Neurociências e Compreensão Leitora: Emoção, Atenção, Memória e Funções Executivas. Rev. FSA, Teresina, v.15, n.4, art. 8, p.151-168, jul./ago. 2018. Disponível em: <http://www4.fsanet.com.br/revista/index.php/fsa/article/view/ 1586/491491586>. Acesso em: 06 maio. 2019.

PRODANOV, C. C.; FREITAS, E. C. D. Metodologia do trabalho científico: Métodos e Técnicas da Pesquisa e do Trabalho Acadêmico. $2^{\mathrm{a}}$. ed. Novo Hamburgo: Universiade Freevale, 2013.

RUSSO, R. M. T. Neuropsicopedagogia Clínica: introdução, conceitos, teoria e prática. Curitiba: Editora Juruá, 2015. 


\section{TTUERARUIS REFLEGTIONIS

SILVA, E. R. V. Despertar Sorrisos à Vida. Um Projecto de Animação Sociocultural numa Instituição Particular de Solidariedade Social. 2011. Disponível em: <http://repositorium. sdum.uminho.pt/bitstream/1822/19240/1/Eduarda\%20Raquel\%20Veloso\%20Silva.pdf> Acesso em: 12 abr. 2019.

SIMÕES, A. A nova velhice. Um novo público a educar. Porto: Ambar. 2006.

VELEDA, Gessyka W. et al. Efeito da terapia cognitivo-comportamental um ano após tratamento para adultos com transtorno depressivo maior.Disponível em: $<$ http://pepsic.bvsalud.org/scielo.php?script=sci_arttext\&pid=S151636872019000300009\&lng=pt\&nrm=iso\&tlng=pt>. Acesso em: 07 jun. 2019.

ZHANG, Li; ZHANG, Tianzhu; SUN, Yan. A newly designed intensive caregiver education program reduces cognitive impairment, anxiety, and depression in patients with acute ischemic stroke. Disponível em: 〈https://www.ncbi.nlm.nih.gov/pubmed/31483000〉. Acesso em: 01 maio. 2019.

ZIMERMAN, G. Velhice, Aspectos Biopsicossociais. Porto Alegre: Artmed Editora. 2000. 